\title{
Los estudios de la audiencia: una visión crítica desde la economía política
}

\author{
José A. Vela Montero \\ Grupo de Investigación en Estructura, Historia y Contenidos de la Comunicación
}

\begin{abstract}
RESUMEN
El autor expone y analiza desde una perspectiva diacrónica la evolución de los estudios culturales desde su nacimiento hasta la actualidad. En especial, este estudio descriptivo se centra en el proceso y las consecuencias del abandono del análisis sociológico marxista y, en concreto, de los postulados de la economía política. Un abandono que, en la práctica, tiene como consecuencia la incapacidad de los estudios culturales para llevar a cabo su objetivo original y fundamental: la transformación social.
\end{abstract}

\begin{abstract}
This article analyses the development of the cultural studies from its birth until present time. Especially, this descriptive study is focus in the process and the consequences of the abandonment of the sociological Marxist analysis and, in short, of the postulates of the political economy. An abandonment that, in the practice, it has as consequence the inability of the cultural studies to carry out their original and fundamental objective: the social transformation.
\end{abstract}

Palabras claves: Estudios culturales/Audiencia/Economía política/Revisionismo/Determinismo/ Productos mediáticos.

Key Words: Economics/Revisionism/Determinism/Media Products.

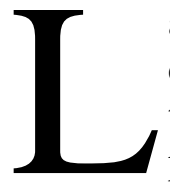

as relaciones entre la economía política y los estudios culturales es uno de los aspectos más conflictivos $-\mathrm{y}$ a la vez más sugerentes y significativos- de los estudios culturales desde que esta disciplina fuera fundada por Raymond Williams. Simplificando -quizás en exceso- los términos del debate, podemos decir que la clave de la discordia entre las posturas científicas en liza es el desplazamiento de la economía política que se ha operado en el seno de los estudios culturales. En un afán de desprenderse del "lastre" que constituía el determinismo económico - principio axial de la sociología marxista tradicionaly en un proceso que se asemeja más a un movimiento pendular que a una evolución en la disciplina, los estudios culturales de los últimos años se han 
centrado en las cuestiones de la recepción y la creación de significados por parte de la audiencia.

Paralelamente, han dejado al margen las circunstancias que rodean a la producción y distribución de los productos simbólicos, es decir, el contexto en el que se elaboran y distribuyen los productos de la cultura: el modo de producción capitalista y el sistema de libre mercado. Al dar de lado a estas cuestiones analizadas por la economía política, los estudios culturales se han incapacitado a sí mismos para alcanzar los objetivos originalmente fijados: la democratización de la cultura y la transformación social. En otras palabras, para asumir los objetivos transformadores de los estudios culturales es necesario encardinar la economía política en el análisis del sistema cultural. Así lo entiende Graham Murdock cuando afirma:

"Puesto que es necesario que cualquier estrategia para el cambio sepa dónde aplicar la presión y qué se debe presionar, el hecho de trazar las conexiones entre las prácticas particulares y las condiciones que las mantienen es un punto de partida indispensable" ${ }^{1}$.

\section{Los estudios culturales en sus orígenes: una dimensión política y transformadora}

En su concepción original, los estudios culturales surgieron, a fines de la década de los 50, como un proyecto político que pretendía una democratización profunda y real y, en última instancia, una transformación de una sociedad sumida en la vertiginosa evolución que, por aquel entonces, estaban posibilitando las nuevas tecnologías aplicadas a la comunicación de masas. Como apuntan Marjorie Ferguson y Peter Golding:

"El proyecto de los estudios culturales siempre ha sido, explícitamente, de alguna manera una intervención en la vida política, una contribución para desenmascarar la ideología y la liberación de la opresión de aquellos que estaban sujetos a su poder represivo"2.

No en vano, la generación de fundadores de los estudios culturales -entre los que destacan Raymond Williams y Richard Hoggart- estaba muy ligada a la

1 MURDOCK, Graham: "Comentarios de base: las condiciones de la práctica cultural", en FERGUSON, Marjorie y GOLDING, Peter (eds.): Economía política y Estudios culturales, Bosch, Barcelona, 1998, p. 168.

2 FERGUSON, Marjorie y GOLDING, Peter: "Los estudios culturales en tiempos cambiantes: introducción", en FERGUSON, Marjorie y GOLDING, Peter (eds.): op. cit., p. 32. 
Nueva Izquierda Británica. Por tanto, los objetivos que se proponían alcanzar los estudios culturales tenían un marcado carácter político y consistían, básicamente, en movilizar a la clase obrera, conseguir una plena democratización de la cultura popular articulada en torno a los medios masivos de comunicación y, de este modo -y como colofón del proceso- alcanzar la transformación social que otorgara el poder político e intelectual a la clase trabajadora. En palabras de Nicholas Garnham:

"La profunda confianza de los estudios culturales en la obra de Raymond Williams y Richard Hoggart fue, en primer lugar, la revalidación de la clase obrera británica o la cultura popular contra la elite, la cultura dominante, como parte de un movimiento político mayoritariamente socialista y de oposición. Por consiguiente, los estudios culturales dieron por sentado una estructura particular de dominación y subordinación y consideraron que su tarea era de legitimación ideológica y movilización. Se consideraron, claramente, parte de una gran batalla política"3.

El medio para conseguir dichos objetivos era desarrollar los estudios culturales, los análisis críticos de la, hasta el momento, ignorada cultura popular, al objeto de concienciar a la clase obrera del valor, magnitud e importancia de su propia cultura. En este sentido, el denominado «Centro de Birmingham»y, en concreto, uno de sus máximos exponentes, Williams, puso de relieve la necesidad, de cara a la consecución de estos objetivos, de implementar las consideraciones de la economía política en los análisis de la cultura popular y de los productos mediáticos que llevan a cabo los estudios culturales. En esta línea, y como muestra evidente de la importancia que tenía la economía política para esta primera generación de estudios culturales, Williams establece que todo producto cultural tiene dos dimensiones inextricablemente unidas: la parte simbólica (consumo) y la parte económica (producción). Al señalar que estas dos dimensiones no deben ser nunca consideradas de forma aislada, el autor toma partido por la necesidad de implementar los análisis de la economía política en los estudios culturales $\mathrm{y}$, de este modo, llama la atención hacia los efectos perjudiciales de abstraer la cultura de su contexto sociopolítico. Los estudios culturales, por tanto, comenzaron haciendo hincapié en la necesidad de que la cultura se investigase en el seno de las relaciones sociales de producción propias del sistema económico en la que se produce, se distribuye y consume. Sin las aportaciones de la economía política, es decir, sin tener en cuenta la producción, codificación y distribución de productos

3 GARNHAM, Nicholas: "Economía política y la práctica de los estudios culturales" en FERGUSON, Marjorie y GOLDING, Peter (eds.): op. cit., pp. 122-123. 
simbólicos y los intereses existentes tras dicha producción, esta disciplina no podría cumplir sus objetivos políticos de democratización y transformación social. En la actualidad, muchos autores siguen reivindicando el componente eminentemente político de los primeros estudios culturales como elemento decisivo para encarar los retos derivados de ser un proyecto político. En este mismo sentido se expresa Garnham:

"Quisiera poner de manifiesto que los estudios culturales como empresa política importante es insostenible desde el exterior de su problemática fundadora. Se puede ver con claridad en las obras contemporáneas de los estudios culturales británicos y norteamericanos que la mayoría de sus actuales profesionales aún asumen, incluso aseveran, que son una empresa política, en su mayor parte, oposicional"4.

\section{El determinismo marxista: planteamientos y revisiones}

"Aquellos que ridiculizan el determinismo económico son aquellos cuyas vidas no están determinadas económicamente" 5 .

Karl Marx señalaba que los medios de producción y las relaciones que contribuyen a la reproducción material de la existencia humana (relaciones de producción) constituyen la base determinante de todas las restantes estructuras. En otras palabras, de las fuerzas y relaciones de producción, así como del modo en que son organizadas socialmente en las diferentes épocas históricas -es decir, la estructura económica de un modo de producción dado- es de donde surgen todas las instituciones de la superestructura (la familia, el Estado, el sistema educativo, la religión, la ideología, las costumbres, la legislación, los medios de comunicación, etc.). He aquí los elementos que constituyen el "modo de producción" y las relaciones que establecen entre sí: una infraestructura económica y una superestructura ideológica, que es determinada por aquella. Marx establece con total precisión esta relación marcada por la determinación entre la superestructura y la infraestructura en el contexto del modo de producción:

\footnotetext{
4 Ibidem, p. 123.

5 SIVANANDAN, A., citado por MURDOCK, Graham: art. cit., p. 182.
} 
"La totalidad de [las] relaciones de producción constituye la estructura económica de la sociedad, sus cimientos reales, sobre los cuales se erige una superestructura legal y política y a la que corresponden unas formas definidas de conciencia social. El modo de producción de la vida material condiciona el proceso general de la vida social, política e intelectual" ${ }^{6}$.

Marx también identifica el fenómeno de la "falsa conciencia" como resultado de la determinación de base económica sobre la superestructura. La "falsa conciencia" plantea el problema de que, en el ámbito supraestructural de las ideas, del valor, de la conciencia, el hombre puede generar una visión, una experiencia sobre su situación y sus condiciones materiales de existencia que puede no corresponder con la verdadera situación determinada por las relaciones y condiciones de producción en las que se halla inserto. Se trataría, pues, de que la propia conciencia y experiencia humanas a través de las cuales el hombre puede explicar la realidad que le rodea y dar sentido a su propia existencia, al estar determinadas por las circunstancias de la producción material, en lugar de propiciar a la clase obrera un conocimiento liberador, la confunde y desorienta distorsionando la verdadera percepción de la realidad y posibilitando, por tanto, la perpetuación de las condiciones de explotación y desigualdad inherentes y necesarias al orden de producción capitalista. Es en este sentido en el que Marx explica la "falsa conciencia" en términos de determinación económica, aludiendo al hecho de que, determinado por las condiciones y relaciones de producción, los hombres (la clase trabajadora) son "descentrados por las condiciones concretas en que viven $y$ producen y dependen de condiciones y circunstancias que no han hecho ellos [y de relaciones que tampoco han establecido] y en las que entran involuntariamente (...) porque los hombres no pueden ser autores colectivos de sus acciones"

Por lo tanto, Marx concluye diciendo que los términos de la conciencia y la experiencia a través de los cuales los hombres dan sentido a su mundo y toman conciencia ("falsa") de su situación, no les pertenecen a ellos, sino a las clases poseedoras de los medios de producción material que, en consecuencia, poseen también los medios de producción mental, lo que determina que las ideas de esta clase poseedora y dominante sean, a su vez, las ideas dominantes de su tiempo, las cuales producen y distribuyen entre los individuos de toda la sociedad a fin de contribuir al mantenimiento, funcionamiento y perpetuación del orden capitalista dominante. Es aquí donde radica el principio de determinación de lo económico

6 MARX, Karl, citado por MURDOCK, Graham y GOLDING, Peter: "Capitalismo, comunicaciones y relaciones de clases", en CURRAN, James; GUREVITCH, Michael y WOOLLACOT, Janet (coords.): Sociedad y comunicación de masas, Fondo de Cultura Económica, México, 1981, p. 26.

7 HALL, Stuart: "La cultura, los medios y el efecto ideológico", en CURRAN, James; GUREVITCH, Michael y WOOLLACOT, Janet (coords.): op. cit., p. 362. 
sobre lo ideológico, principio axial de las relaciones base-superestructura en la teoría marxista clásica, y lo que, en consecuencia, explica la razón por la que los términos de la experiencia y la conciencia de los hombres -determinadas por las condiciones de producción- no reflejan nunca con fidelidad su verdadera situación, sus verdaderas condiciones de existencia material.

Murdock y Golding señalan acertadamente que Marx y Engels están planteando tres cuestiones muy importantes. En primer lugar, que el control sobre la producción y distribución simbólica o intelectual está concentrada en manos de la clase que domina los medios de producción material. En segundo término, y como resultado de ese control, que la visión del mundo de esta clase poseedora se distribuye de forma privilegiada, llegando a dominar el pensamiento de las clases subordinadas. Y, finalmente, que este dominio ideológico tiene asignada la función primordial de perpetuar las desigualdades de clase que sirven a los intereses de reproducción del orden productivo capitalista ${ }^{8}$.

No obstante, y pese a la importancia que reviste el concepto de "determinación económica", en el marco concreto de los estudios culturales dicho concepto necesita una redefinición, una nueva reinterpretación que permita a la disciplina desembarazarse del lastre del reduccionismo economicista y, sobre todo, que haga posible volver a atar las amarras de los estudios culturales a los muelles firmes y rigurosos de la economía política.

Sólo redefiniendo el concepto de determinación en un sentido más abierto, laxo y complejo, que nos hable de marcos o límites genéricos y no de correspondencias ineludibles y necesarias o de efectos plenamente previsibles, se podrá no sólo recuperar las imprescindibles aportaciones con las que la economía política contribuye a los análisis de la cultura (aportaciones de las que, por otra parte, los estudios culturales decidieron prescindir en su abandono de la sociología marxista), sino también la potencialidad explicativa de los análisis sociológicos marxistas.

Williams expresaba una idea similar en cuanto al principio de determinación al señalar que ésta no podía ser nunca (como pretende la teoría marxista ortodoxa) un conjunto de causas que establece un control absoluto con resultados totalmente previsibles. Por el contrario, Williams entendía la determinación de base económica como los límites definidos entre los cuales las prácticas sociales superestructurales se desarrollan influidas en gran medida por la base, pero sin llegar en ningún momento a estar totalmente controladas por los elementos de la estructura económica. Las prácticas sociales supraestructurales pueden, de este modo, estar sujetas a una serie de límites (económicos) y sometidas a un conjunto

8 Cfr. MURDOCK, Graham y GOLDING, Peter: art. cit., pp. 25-26. 
de presiones, pero nunca estarán totalmente controladas ni, en virtud de la determinación, llegan a ser absolutamente previsibles ${ }^{9}$.

De esto se deduce que debemos entender la base económica de la estructura social como factor determinante, en primera instancia, de la vida o el sistema cultural, sin descartar, en consecuencia, la existencia de otros varios factores en la conformación de dicho sistema cultural. Así lo reconocen Murdock y Golding cuando afirman:

“(...) la economía política no es el único determinante del comportamiento de los medios y, en este sentido, no sostenemos una tesis de puro determinismo económico. Sin embargo, al centrarnos en la base económica, indicamos que el control de los recursos materiales y su cambiante distribución es, en última instancia, la más poderosa entre las muchas palancas que trabajan en la producción cultural"'

Así pues, de estos planteamientos se deriva que las condiciones de la producción material serían el punto de partida imprescindible para realizar cualquier análisis cultural. Aceptando este nuevo concepto de determinación, la economía política reaparece en los estudios culturales como un elemento vital para explicar el cómo y el por qué de la organización del sistema cultural, así como el modo de transformarlo.

\section{Estudios culturales y "revisionismo": el desplazamiento de la economía polí- tica en los estudios de la recepción}

Pese a todos estos intentos por redefinir el concepto de determinación económica, fue precisamente el rechazo sistemático hacia dicho determinismo (piedra de toque del análisis marxista) lo que, fundamentalmente, propició la nueva reorientación (y revisionismo) de los estudios culturales hacia lo que se ha dado en llamar «estudios de la recepción» o «estudios de la audiencia», una nueva tendencia que ha lastrado a la disciplina con la incapacidad para analizar de forma global los fenómenos culturales al centrarse de forma exclusiva en las microcuestiones de la audiencia y de la recepción, dejando a un lado las macroprocesos referentes al contexto de la producción y la distribución de los productos culturales, es decir, obviando e ignorando las cuestiones de la economía política. Murdock expresa esta idea citando a Stuart Hall:

9 Cfr. MURDOCK, Graham: art. cit., pp. 177-178.

10 MURDOCK, Graham y GOLDING, Peter: art. cit., pp. 31. 
"Lo que ha resultado del abandono del economicismo determinista no ha sido una forma de pensar alternativa en las cuestiones acerca de las relaciones económicas y sus efectos (...) sino, en su lugar, un gigantesco y elocuente mentís. Como si, puesto que lo económico en el sentido más amplio, definitivamente no 'determina', como antes se suponía que hacía, el movimiento real de la historia 'en última instancia', iéste no existiese en absoluto!" ${ }^{11}$.

Se produce, de esta forma, un desafortunado movimiento pendular en el seno de los estudios culturales: para desembarazarse de la pesada rémora que supone el determinismo economicista, que cierra prematuramente el debate sobre los productos mediáticos al considerarlos simplemente una mera expresión o reflejo "determinado" por las condiciones materiales de producción (es decir, por la infraestructura económica del modo de producción), los nuevos estudios de la recepción acometen una profunda revisión teórica y metodológica en virtud de la cual, no sólo reniegan del determinismo marxista, sino también de los presupuestos de la economía política.

En resumidas cuentas, el problema fundamental radica en que los nuevos estudios de la recepción han abandonado los planteamientos sustentados por la economía política bajo el pretexto del rechazo al principio de determinación, "supuestamente" inherente (según la interpretación revisionista) al análisis de la economía política, es decir, al estudio de las condiciones de producción y distribución de los productos mediáticos. En otras palabras, en la desenfrenada carrera que emprenden los estudios culturales desde la modernidad a la posmodernidad (y desde el compromiso político izquierdista al apoliticismo neoliberal), la economía política hubo de pagar, con su ostracismo, los pecados (determinismo, reduccionismo, economicismo, cosificación estructural) del análisis sociológico marxista.

Puede decirse -sintetizando- que este movimiento pendular, esta nueva tendencia de los estudios culturales hacia unos estudios de la recepción centrados exclusivamente en el análisis de la interacción lector-texto, con la audiencia como objeto de estudio exclusivo y predilecto, arranca originalmente de tres premisas que dieron lugar a una nueva orientación en la disciplina, orientación que no se corresponde para nada con los objetivos políticos y transformadores del proyecto original de Williams. Estas tres premisas son la denuncia del determinismo económico marxista, el rechazo a las tesis marxistas sobre la ideología dominante y la reivindicación de la audiencia como agente activo en el seno de la relación con los medios masivos de comunicación. 
Sin embargo, debido a la exageración y desproporción de los términos, y a la falta de rigor en sus planteamientos, los estudios de la recepción entraron, de este modo, en un callejón sin salida similar a aquel del que pretendían escapar. Huyendo del reduccionismo que suponía para el análisis el determinismo economicista y la dominación ideológica, que cerraban prematuramente el debate de la cultura popular al ignorar las acciones y prácticas de los sujetos por considerarlas producto de la determinación de las condiciones económicas imperantes en la estructura, el movimiento revisionista se precipitó a otra vía muerta que cerraba igualmente en falso el análisis de la cultura al aceptar cualquier práctica cultural del sujeto como "liberadora" o "creativa", sin plantearse las cuestiones referentes al valor o a la capacidad transformadora de dichas prácticas, y sin abordar, paralelamente, el análisis de las condiciones en las que se generan los productos mediáticos, negando así la potencialidad de estas condiciones para ejercer, no ya una determinación total, sino una influencia más o menos directa o abierta sobre la audiencia. En otras palabras, de la mano de los estudios de la recepción, la cultura popular ha pasado de ser el simple reflejo de las condiciones de producción material de un sistema económico, a ser la expresión de la "resistencia" y la "creatividad" de una audiencia totalmente "autónoma" y "soberana", frente a unos medios de comunicación "plurales" e "impotentes" para influir en la sociedad. Todo ello ha sido posible porque -como ya hemos apuntado- el rechazo (lógico y necesario) a los planteamientos excesivamente reduccionistas del determinismo marxista, derivó (de forma injustificable) en la supresión de los postulados de la economía política, imprescindibles para el análisis de los productos mediáticos. Imprescindibles por cuanto desvelan de qué forma y en qué medida dichos productos están estructurados (no determinados) por el sistema de producción dominante y, por tanto, en qué medida están concebidos para propiciar, en el momento de la decodificación, la reproducción de la ideología dominante o, al menos, del conjunto de valores y actitudes que definen y sustentan al sistema capitalista.

En concreto, el cuestionamiento revisionista del concepto de ideología dominante (cuestionamiento propiciado, en gran medida, por el redescubrimiento de las tesis de Gramsci sobre hegemonía y poder) constituyó un nuevo y duro ataque a las almenas de la sociología marxista y, por extensión, a los planteamientos de la economía política. El resultado de esta pretensión de desvincular las condiciones materiales de producción - por un lado- de la ideología dominante -por otro- y de relativizar ésta en exceso (hasta el punto de sostener que, en la práctica, no existe la dominación ideológica), viene a ser el mismo que el que se deriva de llevar hasta el extremo la crítica a la determinación de base económica y la reivindicación de la autonomía de las prácticas y acciones sociales del sujeto: el empobrecimiento, la despolitización, la "conservadurización" y el encastillamiento de los estudios culturales en unos métodos de análisis que, desprovistos de la economía política, apenas tienen nada que aportar a la comprensión de la cultura popular. 


\section{Estudios de la recepción: fundamentos y limitaciones}

Todos estos planteamientos revisionistas en el seno de los estudios culturales fueron gestándose a lo largo de los años 70 para eclosionar, finalmente, a principios de los 80. Hasta bien entrada la década de los 70, el tema de la audiencia fue prácticamente desestimado por muchos teóricos de la comunicación y de la cultura a favor del análisis de las cuestiones relativas a la base económica que establecía los marcos y parámetros en los que se generaban los productos simbólicos, unos productos a los que se suponía la capacidad de ejercer una determinada influencia y de producir unos ciertos efectos sobre los receptores. Sin embargo, a partir de la década de los 80 -y coincidiendo significativamente con el auge en gran parte de Occidente de las doctrinas económicas y políticas conservadoras encabezadas por los gobiernos Reagan y Thatcher- se produjo un florecimiento de los estudios centrados en la recepción y en la audiencia. Tras la década de los 70, rotas las esperanzas de transformación social alimentadas durante esos años, un amplio sector de los estudios culturales abandonó las cuestiones ideológico-políticas y volvió los ojos hacia la cultura popular como arma alternativa para la victoria final sobre la hegemonía de la clase dirigente, ya que dicha cultura tenía como atributos la rebeldía, la vitalidad y el espíritu de oposición y resistencia. Se estaba gestando, de este modo, una nueva perspectiva en los estudios culturales en virtud de la cual, lo político equivalía a lo personal: la caída en el pozo del populismo era ya un hecho. Esto suponía una retirada desde los planteamientos políticos de los estudios culturales originales ya que, al extender un manto de silencio sobre las condiciones materiales de la producción cultural y tomar la cultura popular como objeto exclusivo del análisis cultural, los estudios de la recepción aceptaron subirse al carro de la tendencia posmoderna, sustituyendo, así, la política y la sociedad por la cultura popular. De este modo, la búsqueda de una supuesta resistencia y creatividad de la audiencia se convirtió en una auténtica necesidad. Como refleja irónicamente Todd Gitlin:

"Quizá [las masas] eran libres, o realmente disentían, aunque estuviesen en casa, sentados en el sofá. Si 'la revolución' se había alejado hasta el punto de hacerse invisible, era deprimente presenciar la victoria de una cultura hegemónica impuesta por medios de comunicación, fuertes y prácticamente irresistibles. 'Qué tranquilizador era detectar la 'resistencia' que saturaba los poros de la vida cotidiana!" 12 .

12 GITLIN, Todd: "El populismo antipolítico de los estudios culturales", en FERGUSON, Marjorie y GOLDING, Peter (eds.): op. cit., p. 82. 
La "autonomía" de la audiencia refuta -según la tendencia revisionista- el concepto de medio de comunicación entendido como vehículo a través del cual circulan y se reproducen los discursos dominantes. Paralelamente, surge una nueva imagen de la sociedad en la que el poder para dotar de sentido a dicha sociedad, en lugar de ser atributo de una ideología dominante difundida a instancias del grupo hegemónico, está amplia y "pluralmente" difundido.

En contra de estos planteamientos, el propio David Morley (destacada figura dentro de la corriente revisionista de los estudios culturales) advierte que, pese a que las tesis marxistas sobre la ideología dominante pecan bastante de ingenuidad y aunque cualquier discurso hegemónico es necesariamente ambiguo, incompleto y contradictorio, no se deben abandonar las cuestiones referentes al poder de los medios en brazos de las tesis sobre la "actividad" de la audiencia y sobre las rutinarias lecturas "resistentes"13.

En líneas generales, los nuevos estudios de la audiencia han sufrido -desde el sector radical de los estudios culturales- multitud de contraataques académicos en varios frentes que, a la postre, están relacionados entre sí. Hasta el momento, hemos puesto en tela de juicio el abandono de las macrocuestiones de la economía política en favor de un análisis que, centrado exclusivamente en los microprocesos propios de la recepción, busca reivindicar la "autonomía" y "actividad" de la audiencia. Esta crítica está íntimamente relacionada con la denuncia de las nuevas tendencias populistas de estos estudios de la recepción, derivadas del hecho de haber colocado en el centro del análisis a la cultura popular en detrimento de los medios de comunicación y de las condiciones materiales en las que se generan los productos culturales.

La supuesta "autonomía" de la audiencia (baluarte teórico del nuevo revisionismo de los estudios culturales) ha sido duramente contestada $-\mathrm{y}$ desde diferentes perspectivas- desde la crítica radical. Frente a las tesis revisionistas, que sostienen que los grupos económica e ideológicamente dominantes no influyen en el proceso de comunicación que se establece entre medios de difusión y audiencias, la tendencia radical sostiene que el orden socioeconómico establecido ejerce un poder efectivo en dos momentos clave del proceso comunicativo: en la codificación y en la descodificación.

En cuanto a la codificación de los productos culturales por parte de las industrias de la comunicación, cabe destacar que estos textos no son tan abiertos y ambiguos como se pretende, sino que se concretan en lo que se ha dado en llamar "polisemia estructurada". En virtud de este concepto, los símbolos denotativos del texto propician unas determinadas interpretaciones por parte de las

13 Cfr. MORLEY, David: “Ortodoxias teóricas: textualismo, constructivismo y nueva etnografía”, en FERGUSON, Marjorie y GOLDING, Peter (eds.): op. cit., p. 221. 
audiencias (decodificaciones privilegiadas) que no son fruto exclusivo de su competencia como receptores generadores de sentido, sino que responden a una serie de lecturas preferentes hacia las que los productores del texto orientan mediante "marcas de lectura"- a la audiencia con el fin último de favorecer sus intereses como grupo hegemónico. Hall opina que, aunque los textos son susceptibles de tener más de una interpretación y pese a que no existe ninguna ley que garantice la elección por parte del receptor de la lectura preferencial o dominante, no se puede ignorar que los textos están "estructurados en dominancia" por la industria de la cultura, industria que a su vez forma parte del sistema de producción capitalista. Por lo tanto, y en el contexto de la producción, la codificación ejerce un efecto "sobredeterminante" en momentos posteriores a la recepción. Morley expresa así estas consideraciones sobre la codificación de los productos mediáticos:

"Las audiencias no ven sólo lo que quieren ver, ya que un mensaje (o programa) no es simplemente una ventana abierta al mundo, sino que es una construcción. Aunque el mensaje no sea un objeto con significado real, lleva en sí mecanismos significadores que estimulan ciertos significados, o incluso, un significado privilegiado, y suprimen los demás: se trata de las 'conclusiones directrices' codificadas en los mensajes" ${ }^{14}$.

Por otra parte, en lo relativo a la descodificación llevada a cabo por la audiencia, la corriente crítica de los estudios culturales afirma que los receptores no tienen un repertorio indefinido de discursos de los que valerse para generar significados a partir de los productos culturales. Por el contrario, es la posición socioeconómica de los sujetos receptores en la estructura social la que, por lo general, determinará los tipos de discursos a los que pueden acceder, lo cual determina a su vez la gama de lecturas que pueden inferir de los textos mediáticos. Lo que está sobre el tapete es la cuestión del capital simbólico y el capital económico, puesta ya de relieve por Roland Barthes: frente a la desproporcionada confianza de los "revisionistas" en la actividad generadora de sentido de la audiencia, lo cierto es que el capital simbólico de los sujetos está estrechamente vinculado -en términos de proporcionalidad directa- con el capital económico. Plantear, pues, como hacen los estudios de la recepción, que la audiencia es activa y genera significados a partir de cualquier texto cultural en el contexto de la recepción sin tener en cuenta los condicionamientos y limitaciones que, en este

14 MORLEY, David: "Populismo, revisionismo y nuevos estudios de la audiencia", en CURRAN, James; MORLEY, David y WALDERDINE, Valerie (comps.): Estudios culturales y comunicación, Paidós, Barcelona, 1998, p. 422. 
sentido, establecen las condiciones materiales de producción, es decir, el orden socioeconómico capitalista, equivale a levantar un inmenso gigante con pies de barro.

Las cuestiones relativas a las lecturas "resistentes" y al valor político o transformador de éstas constituyen otro interesante tema de debate que el sector radical de los estudios culturales se ha ocupado convenientemente de poner también en solfa. La presunción, por parte de los estudios de la recepción, de que las interpretaciones presuntamente resistentes de los textos simbólicos están más extendidas que la subordinación o la reproducción de significados dominantes, no sólo implica poner en cuestión tesis excesivamente simplistas sobre los efectos ejercidos por los medios o concepciones demasiado absolutas sobre la ideología dominante. Implica, sobre todo, proclamar la ausencia de toda influencia mediática y de todo condicionamiento y limitación ejercido por el contexto económicoproductivo. Desde el más estricto sentido común, Garnham refuta estas tesis revisionistas sobre la incapacidad del sistema socioeconómico de influir o estructurar los productos mediáticos:

“Acaso alguien que haya producido un texto o una forma simbólica cree que la interpretación es completamente aleatoria o que el placer no puede ser usado con fines manipuladores? Si el proceso de interpretación fuese completamente aleatorio $y$, por consiguiente, tuviésemos que renunciar completamente a la noción de intencionalidad en la comunicación, la especie humana habría abandonado la actividad hace ya bastante tiempo" 15 .

La crítica más pertinente a este respecto es llamar la atención sobre el hecho de que, sin analizar las condiciones económicas de la producción cultural no puede haber lecturas resistentes por parte de la audiencia. Por expresarlo en términos esquemáticos, la resistencia es un concepto, por definición, dual, de tal forma que resistir implica siempre -aparte del sujeto resistente- la existencia o participación del objeto ante el cual se ejerce la resistencia. Por tanto, una lectura resistente -en el contexto de la recepción de la cultura- opone resistencia frente a una serie de valores que, codificados en el texto y a través de su consumo, se intenta imponer a las audiencias por parte de los codificadores. Estos valores codificados en el texto son los elementos constitutivos de la ideología dominante cuya existencia y naturaleza, a su vez, está estrechamente vinculada y delimitada por las condiciones materiales de la producción, es decir, por el orden económico imperante en una determinada sociedad. En consecuencia, si la tendencia revisio- 
nista sostiene que los productos culturales no ejercen ningún tipo de influencia sobre la audiencia, porque no contempla el poder del sistema de producción para estructurar de forma dominante los textos, o -por decirlo de otra manera- si los estudios culturales no creen que los textos contienen sentidos preferentes codificados en el momento de la producción y tendentes a mantener en las conciencias de los receptores los valores y la ideología de los grupos hegemónicos (es decir, tendentes a difundir una "falsa conciencia"), ¿ante qué ejercen resistencia las lecturas resistentes? ¿Contra qué elementos se alza la oposición y la resistencia que, presuntamente, mana de la interpretación de la audiencia creativa?. Como sostiene Morley:

“(...) cuando se nos presenta un ejemplo de una lectura de resistencia (o de oposición), debemos preguntarnos: ¿una resistencia a qué?, porque una noción de resistencia o de oposición sólo adquiere sentido sobre el fondo de cierta concepción de una ideología dominante o una serie de sentidos establecidos de algún modo"16.

De lo expuesto se deriva que la resistencia no puede ser valorada por sí misma como un acto progresista y liberador, sino que debe someterse a un análisis que dilucide si la resistencia o el placer, fruto de la descodificación de un producto cultural, socava o, por el contrario, reproduce la dominación cultural. Para ello resulta indispensable conocer los sistemas de dominación que emanan de las condiciones materiales de producción y que estructuran los productos culturales.

Otro tema sujeto a crítica -en el contexto de los estudios de la recepciónes el del valor de las prácticas culturales y, en especial, de las "lecturas resistentes" de la audiencia. Si se asumen los objetivos políticos y transformadores de los estudios culturales, la discriminación de las prácticas culturales, en función de su aportación a la desestabilización del orden ideológico dominante, es un factor esencial del análisis cultural. Sin embargo, lejos de asumir esta premisa, los estudios de la recepción han llegado a una conclusión errónea: "la audiencia produce significados a partir de los productos mediáticos de la cultura de masas, ergo la cultura de masas es un elemento positivo". Esta conclusión cercena toda posibilidad de transformación del orden cultural establecido, ya que de ella se infiere que los productos mediáticos son "valiosos" en la medida en que son populares. Es decir, la cultura de masas es popular (o sea, tiene éxito) porque es valiosa, de la misma forma que su valor se explica en términos de popularidad. De esta curiosa tautología se infiere una terrible paradoja: si, por una parte, la popularidad es la medida que determina el valor de un producto cultural (o de la

16 MORLEY, David: Televisión, audiencias y estudios culturales, Amorrortu, Buenos Aires, 1996, p. 66. 
cultura de masas en general) y, por otra, la cultura popular es susceptible de difundir sentidos que sostienen la estructura de dominación ideológica, tenemos como resultado que aquello que constata que el receptor está subordinado -la popularidad- confirma, a su vez, el valor de las elecciones culturales de éste. Al no tomar una distancia crítica con respecto a su objeto de estudio -es decir, la cultura popular- los estudios de la recepción han caído en la autocomplacencia populista frente a la cultura de masas. Ello ha hipotecado su aptitud para hablar acerca de la dimensión política de la cultura, al tiempo que ha acercado sus posturas a la ideología hegemónica (o pensamiento único) que se esconde tras esta cultura de masas. Morley cita a Tania Modleski para expresar esta idea:

"Inmersos como están en su propia cultura, casi enamorados de su objeto, con frecuencia [los estudios de la recepción] parecen incapacitados para tomar la necesaria distancia crítica de él. El resultado es que pueden terminar escribiendo involuntariamente verdaderas apologías de la cultura de masas y abrazando la ideología de esa cultura" ${ }^{17}$.

Esto explica por qué el revisionismo cultural no es capaz de admitir que existen prácticas culturales no ya sólo pobres y limitadas en cuanto a alcance político, sino, incluso, prácticas que contribuyen a la sustentación de las estructuras de dominación, al tiempo que retrasan y obstaculizan el cambio social. Por tanto $-\mathrm{y}$ dando por sentado que no todos los sentidos generados por la audiencia a partir de los productos mediáticos son en sí mismos expresiones de poder político- la verdadera "lectura resistente" (es decir, su potencial político) debe rastrearse mediante su sometimiento a los juicios de valor que determinen hasta qué punto tales prácticas culturales facilitan la transformación social o, por el contrario, reproducen y perpetúan las estructuras de dominación. La tendencia revisionista mantiene, justamente, el criterio opuesto: diluye las cuestiones de juicio en el lodo de la "diferencia", asumiendo acríticamente que la "diferencia" entre las distintas prácticas culturales es un valor en sí mismo, con lo cual se abandona el proyecto crítico y político de los estudios culturales. Perder de vista cuestiones como ésta, favorece la argumentación de entelequias tales como la que -en lo relativo a la audiencia- permite establecer una equivalencia entre el "poder" de generar sentidos y el "poder" político-ideológico. Y, a su vez, establecer esta precipitada asociación evidencia el desconocimiento, por parte de los estudios de la recepción, de que el poder para decodificar un texto no es equiparable, de ninguna forma, al poder de los medios para estructurar los sentidos de los productos mediáticos que constituyen la cultura de masas.

17 Ibidem, pp. 60-61. 
Para cerrar esta revisión crítica de los estudios de la audiencia no podemos dejar de subrayar el cada vez más acusado proceso de integración de estos estudios en el ámbito de la ideología conservadora y de la Nueva Derecha política que accedió al poder político en Occidente a principios de la década de los 80 . En efecto, todas las características que definen la naturaleza de los estudios de la audiencia apuntan hacia una creciente identificación entre éstos y las teorías políticas y sociales de la derecha neoliberal.

Un primer punto de contacto entre la tendencia revisionista de los estudios culturales y el neoliberalismo económico -basamento ideológico del modo de producción capitalista- radica en la inestimable colaboración que aquella tendencia ofrece a esta corriente ideológica para dejar al margen del análisis las cuestiones relativas a la producción económica, lo que permite sostener, falazmente, la indeterminación total de las prácticas culturales de la audiencia. Con ello, el capitalismo logra mantener intacta su legitimación, en la medida en que las consideraciones macroestructurales-es decir, las aportaciones de la economía política- que evidencian cómo los productos mediáticos están influidos por el sistema de producción capitalista a fin de difundir una serie de ideas, valores y significados en consonancia con la ideología del bloque de poder dominante, son invariablemente relegadas a un segundo plano.

Otro punto de contacto entre revisionismo cultural y conservadurismo político lo constituye la proclamación, por parte de los estudios de la recepción, de la "soberanía del consumidor" que, en la línea del más puro pluralismo conservador, pretende hacer ver que el individuo es el mejor juez para dilucidar el valor de los productos culturales. Al asumir esta propaganda neoliberal y convertirla en la piedra angular de todo su edificio teórico, los estudios de la audiencia hacen el juego al sistema económico capitalista. Paradójicamente, al afirmar el poder de la audiencia para defenderla del orden socioeconómico imperante, el revisionismo ha conseguido justamente lo contrario, es decir, sacrificar a los sujetos de la audiencia a los intereses económicos del capitalismo. Por otra parte, al hacer prevalecer la condición de "consumidor", los estudios de la audiencia han satisfecho las exigencias productivas del capitalismo. En efecto, el rol de "consumidor" es tanto más útil a los intereses del capitalismo por cuanto que, en oposición al concepto de "subordinado" o "explotado", facilita la despolitización de las acciones y prácticas sociales de los sujetos, así como el mantenimiento del orden social. Hablar en términos de "consumidores" es renunciar a la categoría de clase social en el análisis de la cultura, ya que consumidores son tanto los explotadores como los explotados. Disimuladas, de este modo, las contradicciones sociales bajo el manto del consumo (práctica que iguala socialmente a poseedores y desposeídos), el orden capitalista se asegura su mantenimiento sustituyendo la oposición de los sujetos productores explotados por la aceptación de los sujetos consumidores. Garnham percibe esta pretensión, por parte de la estructura econó- 
mica capitalista, de sustituir al problemático "productor explotado" por el dócil "consumidor soberano". El hecho de que los estudios de la audiencia se centraran más en el consumo que en la producción "se ha interpretado políticamente en manos de la derecha cuyo asalto ideológico ha sido estructurado, en gran parte, por el esfuerzo para convencer a las personas de que se construyan a sí mismas como consumidores en oposición a productores" ${ }^{\prime \prime}$.

\section{La pertinencia de la economía política: un ejemplo práctico}

Para pasar del plano teórico -en el que hemos venido abundando a lo largo de estas páginas- a un nivel más práctico y constatar, de este modo, la importancia de la economía política en el análisis cultural, podemos recurrir al ejemplo de un producto cultural concreto, en este caso, la película norteamericana Los demonios de la noche. El film, protagonizado por Michael Douglas y Val Kilmer y ambientado en el África colonial decimonónica, cuenta la historia de una pareja de leones que, lanzados a una orgía de sangre, se dedican a devorar a los trabajadores indígenas que están construyendo una vía de ferrocarril, con la consiguiente extensión del pánico por toda la región. Ante esta situación desesperada, Val Kilmer, que interpreta al ingeniero encargado de ejecutar las obras de infraestructura ferroviaria, y Michael Douglas, un cazador profesional, colaboran codo con codo -con la ayuda de un indígena local- para acabar con el terrorífico dúo felino.

Hablando en términos de niveles de lectura (recurriendo, de este modo, a la clasificación de Yuri Lotman), podemos constatar que en el primer nivel (en el nivel superficial), el espectador decodifica el film extrayendo el sentido de que el ingeniero y el cazador (ambos de raza blanca) pretenden librar a las gentes nativas de un peligro terrible y devolver la tranquilidad y la prosperidad a esas tierras. Es decir, el primer nivel de lectura se concreta en términos simples de héroes protagonistas (los hombres blancos) y villanos antagonistas (las fieras). Sin embargo, es en el segundo nivel de lectura (el de la estructura profunda del texto, cuyo sentido es más difícil de desentrañar que el del primer nivel) donde, centrando el producto cultural (la película) en el contexto de las condiciones económicas de su producción, obtenemos una interpretación alternativa. En este caso, el hombre blanco deja de ser el héroe salvador de los indígenas para convertirse en el paradigma de la explotación y del expolio de unos hombres y una tierra a los que quiere sacar el máximo partido económico. A partir de aquí, podemos interpretar que el ingeniero joven quiere acabar con los leones no para salvar las vidas de sus trabajadores sino para terminar de construir la vía de ferrocarril, que no es un factor de progreso para esa tierra -como se pretende hacer ver en la película- sino 
un instrumento para facilitar la explotación a través de la optimización del sistema de transportes que ha de llevar las materias primas desde el interior, donde son extraídas, hasta los puertos para su posterior viaje a las industrias de la metrópoli colonial. Para completar el análisis, cabría identificar la figura del guía indígena con la imagen del nativo sumiso y colaboracionista del que el poder imperialista extranjero se sirve para imponer su dominio sobre el resto de la población, ubicándolo en puestos de responsabilidad dentro de la administración local.

El sistema de producción en el que se ha generado la película -y sobre el cual la economía política llama la atención en el análisis de los estudios culturalesdetermina en gran medida unos valores ideológicos que, codificados en el producto cultural, propician que la lectura patente (primer nivel de lectura) predomine sobre la lectura latente (segundo nivel). Esta película es un producto típicamente hollywoodiense y, por tanto, norteamericano. Siendo, pues, Estados Unidos el paladín del imperialismo económico y del colonialismo cultural es normal, pues, que se codifique este producto cultural de acuerdo a una serie de valores constitutivos de una ideología dominante derivada del sistema de producción económica imperante. De este modo, la codificación (o estructuración en dominancia) a la que se somete a este texto en el momento de su producción, propicia que la interpretación sociológica de este film se diluya en una simple confrontación entre héroes y villanos, al tiempo privilegia un determinado significado, una lectura preferente: la de que los efectos del colonialismo son beneficiosos no sólo para los poderes económicos metropolitanos, sino también para los propios pueblos colonizados. Sin embargo, el contraste entre los dos niveles de lectura del film queda patente al recurrir a otras interpretaciones sobre el fenómeno colonial:

"El objetivo de política económica colonial, a través de la construcción de infraestructuras de carreteras y ferrocarriles, era vincular únicamente las minas y las plantaciones con los puertos y aeropuertos, con la aquiescencia de una minoría de indígenas. Se buscaba una eficiente administración, una explotación máxima de los recursos y el mantenimiento del orden, sin preocuparse del cuidado de la economía local" 19 .

19 KABUNDA, Mbuyi: "Europa-África: Nueva colonización política, militar, cultural y económica" en Autogestión, núm. 34, junio-julio 2000, p. 


\section{Conclusión}

La principal conclusión que cabe extraer de las reflexiones expuestas en estas páginas es la de que el objetivo político y emancipador de los estudios culturales requiere, más que el simple análisis de las prácticas culturales, la indagación de las condiciones político-económicas que rodean y dan forma a dichas prácticas. Para alcanzar este objetivo político es imprescindible el concurso de la economía política desde una posición no ya secundaria sino central. Este es, en definitiva, el principal argumento de estas páginas: la necesidad del reencuentro y la colaboración de los estudios de la audiencia y de la economía política crítica sobre la base de la centralidad de ésta como parte integral y fundamental de unos estudios culturales comprometidos con la subversión de los valores y del orden capitalista, y con la transformación del sistema cultural y de la sociedad en general. Sirva para ilustrar esta idea la contundente afirmación de Nicholas Garnham:

"Para trasladar y cumplir las promesas de su proyecto original, los estudios culturales ahora necesitan reconstruir los puentes hacia la economía política que quemaron en su precipitada huida hacia los placeres y las diferencias del posmodernismo" 20 .

\section{Bibliografía:}

- CURRAN, James; GUREVITCH, Michael y WOOLLACOT, Janet (coordinadores): Sociedad y comunicación de masas, Fondo de Cultura Económica, México, 1981.

- CURRAN, James; MORLEY, David y WALKERDINE, Valerie (compiladores): Estudios culturales y comunicación, Paidós, Barcelona, 1998.

- FERGUSON, Marjorie y GOLDING, Peter (editores): Economía política y Estudios culturales, Bosch, Barcelona, 1998.

- KABUNDA, Mbuyi: "Europa-África: Nueva colonización política, militar, cultural y económica" en Autogestión, núm. 34, junio-julio 2000, Grupo Solidaridad.

- MARTÍN-BARBERO, Jesús: De los medios a las mediaciones. Comunicación, cultura y hegemonía, Gustavo Gili, Barcelona, 1987.

- MARX, Karl y ENGELS, Friederich: La ideología alemana, Universitat de València, Valencia, 1994. 
210 Los estudios de la audiencia: una visión crítica desde la economía política

- MATELART, Armand y Michèle: Historias de las teorías de la comunicación, Paidós, Barcelona, 1997.

- MORLEY, David: Televisión, audiencias y estudios culturales, Amorrortu, Buenos Aires, 1996.

- MOSCO, Vincent: Fantasías electrónicas, Paidós, Barcelona, 1986.

(Recibido el 2-11-2000, aceptado el 28-11-2000) 